\title{
Status of maternal care and immunisation services in a hilly state of north India: a cross sectional study
}

\author{
Anupam Parashar*, Salig Ram Mazta, Dineshwar Singh Dhadwal, Anita Thakur, \\ Harshvardhan Singh, Kamlesh Sharma, Kanica Kaushal, Sudhir Singh
}

Department of Community Medicine, Indira Gandhi Medical College, Shimla, Himachal Pradesh-171001, India

Received: 29 May 2016

Accepted: 01 July 2016

\author{
*Correspondence: \\ Dr. Anupam Parashar, \\ E-mail: anupamvikrant@yahoo.co.in
}

Copyright: (C) the author(s), publisher and licensee Medip Academy. This is an open-access article distributed under the terms of the Creative Commons Attribution Non-Commercial License, which permits unrestricted non-commercial use, distribution, and reproduction in any medium, provided the original work is properly cited.

\begin{abstract}
Background: Maternal health refers to the health of women during pregnancy, childbirth and the postpartum period. While motherhood is often a positive and fulfilling experience, for too many women it is associated with suffering, ill-health and even death. The objective of this study was to assess the utilisation of maternal health care services and coverage of maternal Tetanus immunisation in six districts of Himachal Pradesh, India.

Methods: A cross-sectional study was conducted using the WHO cluster sampling method during the period October 2015 to January 2016 among children of 0-11 month age covering 1,260 children in total.

Results: A total of 21,097 households were surveyed in 180 clusters. Card availability was $81.1 \%$ and $95.9 \%$ recalled receiving the antenatal card and tetanus immunisation during their respective pregnancies. Out of the total of 1,260 infants surveyed, 1,255 (99.6\%) were found to be fully protected against neonatal tetanus and only $5(0.39 \%)$ were found not to be fully protected. 1,241 $(98.5 \%)$ of the mothers had undergone full Antenatal check-ups (ANC) during their pregnancy. $210(100 \%)$ had at least one ANC. All had undergone the ANC at the nearest government health facility. 1055 (83.7\%) deliveries were institutional deliveries and 201 (16\%) were home deliveries. Overall, deliveries conducted by skilled personnel stood at $91.3 \%$.

Conclusions: Overall, the utilisation of maternal health services and immunisation against maternal and neonatal Tetanus are excellent in the state. The coverage targets for key RMNCH and A, an interventions have been well achieved in the state. Further, sustained efforts with Supportive Supervision are required to achieve 100\% universal coverage of immunisation and full utilisation of maternal health care services.
\end{abstract}

Keywords: Maternal care, Tetanus immunisation, Institutional deliveries

\section{INTRODUCTION}

Maternal health refers to the health of women during pregnancy, childbirth and the postpartum period. While motherhood is often a positive and fulfilling experience, for too many women it is associated with suffering, illhealth and even death. ${ }^{1}$

Antenatal care is one of the four most important pillars of safe motherhood along with family planning, safe delivery and essential obstetric care. ${ }^{2}$
Utilisation of health services is a complex behavioural phenomenon. In developing countries, health seeking behaviours and health care services utilisation patterns have been studied and the determinants have been classified in physical, socio-economic, cultural and political contexts.

Maternal mortality ratio in India is $167 / 100,000$ live births despite the existence of National program for improving the maternal and child health. ${ }^{3}$ Most of the maternal deaths can be prevented if women have access 
to basic antenatal, natal and postnatal care. In India, these services are provided by government through a network of health centres at various levels in out-patient clinics, as well as through home visits by health workers.

Various government schemes are in place to support maternal health. The 'National rural health mission' promoted institutional deliveries with a focus on the poor. ${ }^{4}$ In year 2005, 'Janani Suraksha Yojana' was implemented countrywide to reduce overall maternal mortality ratio and infant mortality rate by promoting institutional deliveries from all the sections of society. ${ }^{5}$

Despite a tough terrain, Himachal Pradesh, a north Indian state fare quite well in the health indicators as compared to other states. The female literacy rate of the state is $76.60 \%$ as compared to the national average of $65.46 \%$. Infant mortality rate in the state is $35 / 100$ live births against a national average of $40 .^{3}$ Now, India has achieved a momentous public health feat - the elimination of maternal and neonatal tetanus. Maternal and neonatal tetanus is reduced to less than one case per 1000 live births in all 675 districts of the country. WHO has validated this achievement adding India to the list of countries that have successfully battled this killer disease. $^{6}$

The recently concluded district level household and facility survey-4, 2012-13 and National family Heath Survey-3 have reported a low coverage of infant and maternal immunisation, thus warranting a state wide survey which was conducted by the department of Community Medicine, Indira Gandhi Medical College, Shimla under the aegis of the National Health Mission, Himachal Pradesh. The DLHS-4 has reported a full antenatal care received by pregnant women at a mere $41.1 \%$ and those receiving more than 3 ante-natal check-ups at $58.3 \%$ in the state. ${ }^{7}$

Hence, this study envisaged to assess the quality of maternal health services and the pattern of utilisation in the state which has a tough terrain and providing services in some areas can be really challenging.

The objective of this study was to assess the utilisation of maternal health care services in six districts of Himachal Pradesh. And assess the coverage of maternal tetanus immunisation in mothers of children 0-11 months old.

1. To assess the utilization of maternal health care services in six districts of Himachal Pradesh.

2. To assess the coverage of maternal Tetanus immunisation in mothers of children 0-11 months of age.

\section{METHODS}

A cross-sectional study was conducted in the six districts of Himachal Pradesh using the World Health Organization's 30 cluster sampling method for evaluation of immunisation coverage during the period Oct 2015Jan 2016 by the department of Community Medicine, Indira Gandhi Medical College, Shimla under the aegis of National Health Mission, Himachal Pradesh.

The period of this study was conducted from October 2015 to January 2016.

The sampling design of this study start with: $30 \times 7$ cluster sampling design developed by WHO in 1978 was adopted. ${ }^{8}$ The goal of this sampling design was to estimate immunisation coverage within \pm 10 percentage points of the true proportion, with $95 \%$ confidence.

\section{Calculation of sample size and selection of clusters}

A total of six districts were selected for the study as a part of the immunisation coverage survey. Equal representation was given to three zones based on altitude.

Lower zone districts were Bilaspur and Mandi (altitude: 250- 1000 metres), Middle zone districts- Solan and Sirmaur (altitude: less than 2000 metres) and upper zone districts were Shimla and Kinnaur (altitude above 2000 metres). ${ }^{9}$

The study sample included 30 clusters from the entire population of each district, a total of seven children aged 0-11 months were taken in each cluster, thus giving us the sample size of 210 . As we took 6 districts in this study, a total $210 \times 6=1260$ children (210 in each district) aged 0-11 months of age were included in this survey for evaluation of maternal immunisation and other parameters related to antenatal and delivery services. 30 clusters were chosen from a single district to explore the possibility of presence of any pockets with un-immunized children or mothers if any and look into the factors responsible thereof.

\section{Strategy for data collection}

Five teams were prepared for each district. Each team comprised of two members who stayed in the allotted cluster at a stretch till the desired sample was reached. The entire district clusters were covered within a span of fifteen days. A single team comprised of either an intern and/or a postgraduate student and and/or a Social worker from the Community Medicine Department. The senior residents acted as supervisors and one Consultant from the department was overall in-charge of each district. The team was constructed in such a manner that, preferably, one of the members was familiar with the local area and language. Selected clusters were allotted to the teams after initial training of the team members with regard to the method of data collection.

Identification of random House hold $(\mathrm{HH})$ after entering the village/ward (cluster) was done in consultation of the village pradhan/ward member/local leader. After taking informed consent, mothers were asked about the 
immunisation received by them and regarding other variables, and this information was verified by crosschecking the mother's vaccination card. In case, the sample of 7 children $0-11$ months of age was not collected from the selected village, the adjoining village was included to reach the desired sample size.

\section{Proof of immunisation}

The child was considered as fully protected or not protected against neonatal Tetanus based on information on the antenatal card. For those without a card, information from the mother was gathered to know whether she had been immunized. If the mother could not recollect anything about the vaccination, the child was considered as not protected. In case of a partial/nonimmunisation, the most important single reason for not receiving immunisation was asked.

\section{Statistical analysis}

The data was entered into and analyzed using Microsoft Excel software and the findings are given in percentages.

\section{RESULTS}

In the total 180 clusters, a total of 21,097 households were surveyed in the six districts of Himachal Pradesh for evaluation of the maternal immunisation coverage to complete the sample size as per the WHO methodology (Table 1). The average number of household visited per cluster were 117 with the most in district Kinnaur (146.83)which is sparsely populated and the least in district Bilaspur (93.3).

Table 1: Details of maternal care services utilised cluster-wise.

\begin{tabular}{|c|c|c|c|c|c|c|}
\hline & Sirmaur & Solan & Shimla & Kinnaur & Bilaspur & Mandi \\
\hline Total population & $\begin{array}{l}5,29,855 \\
(68,65,000-\mathrm{HP})\end{array}$ & $5,80,320$ & $8,14,010$ & 84,121 & $3,81,956$ & $9,99,777$ \\
\hline $\begin{array}{l}\text { Average literacy } \\
\text { rate }\end{array}$ & $\begin{array}{l}78.80 \% \\
(82.8 \%-\mathrm{HP})\end{array}$ & $83.68 \%$ & $83.64 \%$ & $80 \%$ & $84.59 \%$ & $81.53 \%$ \\
\hline $\begin{array}{l}\text { Female literacy } \\
\text { rate }\end{array}$ & $\begin{array}{l}71.36 \% \\
(75.9 \%-\mathrm{HP})\end{array}$ & $76.97 \%$ & $77.13 \%$ & $70.96 \%$ & $77.97 \%$ & $73.66 \%$ \\
\hline $\begin{array}{l}\text { Total clusters } \\
\text { covered }\end{array}$ & 30 & 30 & 30 & 30 & 30 & 30 \\
\hline $\begin{array}{l}\text { Total households } \\
\text { visited }\end{array}$ & 2978 & 3345 & 4198 & 4405 & 2798 & 3373 \\
\hline $\begin{array}{l}\text { Total children } \\
\text { covered }\end{array}$ & 210 & 210 & 210 & 210 & 210 & 210 \\
\hline Full ANC visits & $206(98.1 \%)$ & $206(98.1 \%)$ & $210(100 \%)$ & $204(97.1 \%)$ & $206(98.1 \%)$ & $209(99.5 \%)$ \\
\hline Any ANC & $210(100 \%)$ & $207(98.6 \%)$ & $210(100 \%)$ & $209(99.5 \%)$ & $209(99.5 \%)$ & $210(100 \%)$ \\
\hline $\begin{array}{l}\text { Fully protected } \\
\text { against NT }\end{array}$ & $208(99 \%)$ & $208(99 \%)$ & $210(100 \%)$ & $209(99.5 \%)$ & $210(100 \%)$ & $210(100 \%)$ \\
\hline $\begin{array}{l}\text { Not fully protected } \\
\text { against NT }\end{array}$ & $2(1 \%)$ & $2(1 \%)$ & 0 & $1(0.5 \%)$ & 0 & 0 \\
\hline Card available & $160(76 \%)$ & $166(79 \%)$ & $156(74.3 \%)$ & $177(84.2 \%)$ & $189(90 \%)$ & $174(82.9 \%)$ \\
\hline $\begin{array}{l}\text { Card ever } \\
\text { received }\end{array}$ & $202(96.2 \%)$ & $199(94.8 \%)$ & $194(92.4 \%)$ & $208(99 \%)$ & $198(94.3 \%)$ & $208(99 \%)$ \\
\hline $\begin{array}{l}\text { Institutional } \\
\text { delivery }\end{array}$ & $167(79.5 \%)$ & $175(83.3 \%)$ & $177(84.3 \%)$ & $180(85.7 \%)$ & $174(82.9 \%)$ & $182(86.7 \%)$ \\
\hline Home delivery & $41(19.5 \%)$ & $33(15.7 \%)$ & $33(15.7 \%)$ & $30(14.3 \%)$ & $36(17.1 \%)$ & $28(13.3 \%)$ \\
\hline $\begin{array}{l}\text { Home delivery } \\
\text { by TBA }\end{array}$ & 24 & 21 & 19 & 6 & 12 & 13 \\
\hline $\begin{array}{l}\text { Delivery by } \\
\text { skilled personnel }\end{array}$ & $191(91 \%)$ & $196(93.3 \%)$ & $196(93.3 \%)$ & $186(88.5 \%)$ & $186(88.5 \%)$ & $195(92.8 \%)$ \\
\hline $\begin{array}{l}\text { Utilisation of } \\
\text { govt. health } \\
\text { institutions for } \\
\text { ANC }\end{array}$ & $210(100 \%)$ & $207(98.6 \%)$ & $210(100 \%)$ & $209(99.5 \%)$ & $209(99.5 \%)$ & $210(100 \%)$ \\
\hline
\end{tabular}


During the household visits, Antenatal card was available with $81.1 \%$ of the mothers. $95.9 \%$ recalled receiving the antenatal card and tetanus immunisation during their respective pregnancies. Out of the total of 1,260 infants surveyed, $1255(99.6 \%)$ were found to be fully protected against neonatal tetanus and only $5(0.39 \%)$ were found to be not fully protected. $1241(98.5 \%)$ of the mothers had undergone full Antenatal check-ups (ANCs); (defined as at least 3 ANCs) during their pregnancy. All the mothers i.e $210(100 \%)$ had at least one ANC. All of them underwent the ANC at the nearest government health facility. Out of the total deliveries, 1055 (83.7\%) deliveries were institutional deliveries and $201(16 \%)$ were home deliveries. Of the 201 home deliveries, 95 $(47.2 \%)$ were conducted by trained birth attendants. Overall, deliveries conducted by skilled personnel stood at $91.3 \%$ (Table 2).

Table 2: Comparison of current study on key indicators with DLHS-4 and NFHS-3.

\begin{tabular}{|llll|}
\hline & DLHS-4 (\%) & NFHS-3 & Our study \\
\hline Pregnant women who received any antenatal check-up & 92.3 & - & $100 \%$ \\
\hline Pregnant women who had three or more ANC visits & 58.3 & 62.6 & $98.5 \%$ \\
\hline Pregnant women who had at least one tetanus toxoid injection & 89.7 & - & $99.6 \%$ \\
\hline Institutional delivery & 77.8 (SRS13-74.4\%) & 45.3 & $83.7 \%$ \\
\hline Delivery at home & 21.4 & - & $16 \%$ \\
\hline Delivery at home conducted by skilled health personnel & 15.6 & - & $44.2 \%$ \\
\hline Delivery attended by skilled health personnel & 93.4 & 50.2 & $91.3 \%$ \\
\hline
\end{tabular}

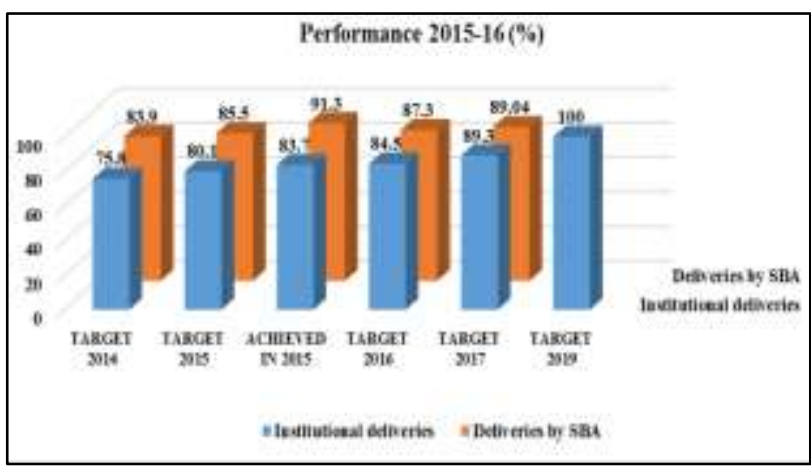

Figure 1: Depiction of targets and performance.

\section{DISCUSSION}

The present study was conducted as a part of the Immunisation coverage survey conducted by the department of Community Medicine, Indira Gandhi Medical College, Shimla under the aegis of National Health Mission, Himachal Pradesh, India.

The DLHS-4 and NFHS-3 reported the percentage of women who received at least three antenatal check-ups during their pregnancy to be $58.3 \%$ and $62.6 \%$ respectively. The proportion of institutional deliveries has been reported to be $77.8 \%$ by DLHS- 4 and $45.3 \%$ by NFHS-4. The SRS 2013 reported it to be $74.4 \%$ of the total deliveries. $3,7,10$

Our study reported the proportion of women who received at least three ANCs to be $98.5 \%$ and $100 \%$ for those who received at least one ANC. Institutional deliveries were found to be $83.7 \%$ thus reflecting an excellent utilisation of the services which further reflects the level of awareness of the public regarding the health services available to them and improved efforts of the related health staff. Even the tribal and hard to access districts like Kinnaur and Sirmaur have reported to have an excellent coverage of immunisation and utilisation of antenatal services which is far higher than the earlier surveys.

The results of a recent study conducted in north India by Gupta RK et al revealed that $79.1 \%$ of the deliveries were institutional. ${ }^{11}$ Another recent study by Roy MP et al conducted in north central India, a total of $85.5 \%$ of were found to have had at least three antenatal check-ups during their pregnancy revealing a high utilisation of the services. $^{12}$

The tribal district of Kinnaur has the second lowest proportion of home deliveries among the six districts $(14.3 \%)$ despite having the lowest female literacy rate $(70.9 \%)$ as compared to $75.9 \%$ of the state. ${ }^{13}$ The Neonatal Tetanus immunisation coverage is $99.5 \%$ and deliveries by skilled personnel were $88.5 \%$. The district of Sirmaur, which is one of the two backward districts of the state receiving the Backwards regions grant fund, has a $99 \%$ coverage against Neonatal tetanus and $91 \%$ deliveries were conducted by skilled personnel reflecting an excellent performance and utilisation of services. ${ }^{14}$

These findings can be attributed to the favorable conditions in the state. The state of HP ranks $11^{\text {th }}$ in terms of average literacy rate which is $82.80 \%$ and the female literacy rate is $75.93 \%$ as compared to the nation i.e $74.04 \%$ and $65.46 \%$ respectively. The state has a good annual per capita income of ₹92,300 as compared to the national average of ₹74,380. ${ }^{15}$

In addition, various national programme such as "Janani Suraksha Yojna" and JSSK etc. which are being 
implemented by the dedicated field health staff and the recently introduced ASHA workers do contribute to the increased overall performance of the health indicators by utilisation of the services.

Our study was unique in the aspect that the survey was conducted by skilled professionals having qualifications in Social work and post-graduates in Community Medicine having ample fieldwork experience. The standard methodology and questionnaire was adopted from WHO which had selected parameters thus ensuring a high quality of data generation.

Although the study was conducted by adopting the most widely used methodology and skilled manpower, the limitations could be limited number of parameters included in the study tools and a possible recall bias while reporting having received immunisation in cases of non-availability of cards.

\section{CONCLUSION}

Overall, the maternal health services utilisation including immunisation against maternal and neonatal tetanus is excellent in the state of Himachal Pradesh. Maternal and Neonatal Tetanus have been recently eliminated from the country. The coverage targets for key $\mathrm{RMNCH}$ and $\mathrm{A}$, an interventions have been well achieved in the state. Further, sustained efforts with supportive supervision are required to achieve $100 \%$ universal coverage of immunisation and full utilisation of maternal health care services especially institutional deliveries.

\section{ACKNOWLEDGEMENTS}

The authors acknowledge funding support from The National Health Mission, Himachal Pradesh for the survey. Authors express his heartfelt gratitude to the Mothers of the six districts of HP where this survey was conducted for their invaluable time and cooperation. We would further like to specially thank the village Pradhans, Ward members and other Panchyati Raj representatives for their cooperation in conducting the field visits.

Funding: The National Health Mission, Himachal Pradesh, India

Conflict of interest: None declared

Ethical approval: The study was approved by the Institutional Ethics Committee

\section{REFERENCES}

1. World Health Organization WHO. Maternal health. Available at http://www.who.int/topics/ maternal_health/en/. Accessed on 24 May 2016.

2. World Health Organization. Mother-baby package: Implementing safe motherhood in countries. Available at http://www.who.int/topics/ maternal_health/en/. Accessed on 25 May 2016.
3. Census of India: SRS Statistical Report 2013. Available at http://www.censusindia.gov.in/ vital_statistics/SRS_Reports_2013.html. Accessed on 25 May 2016.

4. Governnment of India. Reproductive, Maternal, Newborn, Child and Adolescent Health. Available at http://nrhm.gov.in/nrhm-components/rmncha/reproductive-maternal-newborn-child-andadolescent-health.html. Accessed on 25 May 2016.

5. Governnment of India. Ministry of Health and Family Welfare. Available at http://nrhm.gov.in/nrhm-components/rmncha/maternal-health/janani-surakshayojana/background.html. Accessed on 25 May 2016.

6. World Health Organization. WHO congratulates India on Maternal and Neonatal Tetanus Elimination. Available at http://www.searo.who.int/mediacentre/ features/2015/maternal-and-neonatal-tetanuselimination/en/. Accessed on 25 May 2016.

7. District Level Household and Facility Survey. Available at http://rchiips.org/DLHS-4.html. Accessed on 25 May 2016.

8. World health Organization. WHO Immunisation survey.pdf. Available at http://www.who.int. Accessed on 25 May 2016.

9. Government of Himachal Pradesh, India. Available from: http://himachal.nic.in/. Last accessed on 25.5.2016.

10. National Family Health Survey. Available at http://rchiips.org/nfhs/himachal_report.shtml. Accessed on 25 May 2016.

11. Shora T, Verma A, Jan R, Gupta R. Knowledge regarding antenatal care services, its utilisation, and delivery practices in mothers (aged 15-49 years) in a rural area of North India. Trop J Med Res. 2015;18(2):89.

12. Roy MP, Mohan U, Singh SK, Singh VK, Srivastava AK. Determinants of utilisation of antenatal care services in rural Lucknow, India. J Fam Med Prim Care. 2013;2(1):55-9.

13. Government of India. Census of India. Himachal Pradesh Population Sex Ratio in Himachal Pradesh Literacy rate data. Available at http://www.census2011.co.in/census/state/himachal+ pradesh.html. Accessed on 25 May 2016.

14. Government of India. Ministry of Panchyati Raj. A note on the backward regions grant fund programme, 2009. Available at http://www.nird.org.in/brgf/doc/ brgf_BackgroundNote.pdf. Accessed on 25 May 2016

15. GDP per capita of Indian States. Indian states GDP per capita 2015 - StatisticsTimes.com. Available at http://statisticstimes.com/economy/gdp-capita-ofindian-states.php. Accessed on 25 May 2016.

Cite this article as: Parashar A, Mazta SR,

Dhadwal DS, Thakur A, Singh H, Sharma K, et al. Status of maternal care and immunisation services in a hilly state of north India: a cross sectional study. Int J Reprod Contracept Obstet Gynecol 2016;5:2607-11. 